\section{ONOMÁVADIN}

Revista semestral de lingüística, filología y traducción
PONTIFICIA UNIVERSIDAD

\title{
Expectativas de los estudiantes taiwaneses de español: una entrevista a principiantes universitarios
}

Expectations of Taiwanese university students of Spanish as a Foreign Language: an interview with beginners

\section{Maximiano Cortés Moreno}

Universidad Católica Fujen

Taiwán 


\section{Resumen}

En el presente trabajo exponemos los resultados de una entrevista realizada a 30 alumnos de $1 .{ }^{\text {er }}$ curso del Departamento de Español de la Universidad Fujen (Taiwán) a principios de 2013. Dicha entrevista consta de 20 ítems en torno a diversos aspectos del aprendizaje del español: las asignaturas que deben cursar los alumnos, los materiales utilizados en clase, la utilidad del español para su vida actual y futura, etc. Los datos obtenidos en la entrevista ponen de manifiesto que los universitarios taiwaneses tienen una opinión formada y razonada acerca de qué asignaturas, qué materiales didácticos, qué actividades de aprendizaje y qué métodos de enseñanza se adaptan mejor a sus intereses y necesidades. Esta investigación en el aula para la acción tiene como propósito averiguar en qué medida la oferta docente está en condiciones de satisfacer sus expectativas discentes.

Palabras clave: español como lengua extranjera; diseño curricular; alumnos taiwaneses; motivación; enseñanza centrada en el alumno.

\section{Abstract}

In this paper we are releasing the results of an interview conducted with 30 first-year students in the Spanish Department at Fu Jen University (Taiwan) at the beginning of 2013. The said interview includes 20 items related to several aspects of the foreign language learning process, such as school subjects, materials used in the classroom, students' use of Spanish at present and in the future, etc. The data gathered at the interview show that Taiwanese students are perfectly aware of which subjects, learning activities, learning materials, and teaching methods best suit their interests and needs. This research aims at finding out to what extent our teaching offer is liable to match our students' expectations.

Keywords: Spanish as a foreign language; curriculum design; Taiwanese students; motivation; studentcentered teaching. 


\section{Introducción}

En el presente trabajo damos a conocer algunos de los resultados obtenidos en nuestro último proyecto de investigación, titulado Aumento de la motivación de los universitarios taiwaneses por el aprendizaje del español mediante una adaptación del currículo actual (N. ${ }^{\circ}$ 101-2410-H030-060) y patrocinado por el Taiwan National Science Council, al que reiteramos nuestro más sincero agradecimiento. Quedamos asimismo profundamente agradecidos a nuestras dos eficientes ayudantes, Belinda e Hilaria.

Este trabajo es, por un lado, continuación de Cortés Moreno (2012b), donde se publican los resultados de otra entrevista (con los mismos 20 ítems de esta) realizada a un total de 50 alumnos del Departamento de Español de la Universidad Fujen (Taiwán), repartidos entre los 4 cursos de la carrera; en esta ocasión entrevistamos a 30 nuevos alumnos. Por otro lado, es complementario de Cortés Moreno (2013a), donde se exponen los resultados de una encuesta realizada a los mismos 30 alumnos que entrevistamos aquí + otros 67 compañeros, también principiantes de ELE en la Universidad Fujen. Todas estas encuestas y entrevistas, al igual que otras publicadas anteriormente (Cortés Moreno, 2001, 2009, 2011, 2012a, etc.), tienen como primer objetivo analizar la motivación de los universitarios taiwaneses por el aprendizaje del español como lengua extranjera (ELE) y sus preferencias en cada uno de los componentes del proceso instructivo. A partir de ahí, nuestro segundo propósito es averiguar en qué medida la oferta educativa universitaria se ajusta a la demanda discente. En última instancia, nuestra aspiración es descubrir posibles desajustes y, en su caso, plantear unas líneas de actuación que permitan reformar el currículo, adaptándolo a las expectativas de los alumnos taiwaneses en el siglo XXI. Partimos de la premisa de que la motivación es un factor clave para alcanzar el éxito en el aprendizaje de una lengua extranjera.

El campo de investigación sobre la motivación por el aprendizaje de una segunda lengua (L2) lo inauguraron en Canadá R. Gardner y sus colegas a mediados del siglo XX. De entre las obras clásicas publicadas en torno a la motivación por el aprendizaje de una L2 o de una lengua extranjera (LE), cabe resaltar las de Gardner (1985), Dörnyei (2001a y 2001b) y Lorenzo (2007)1.

Si nos ceñimos al área concreta de la motivación por el ELE en Taiwán, probablemente, el primer trabajo sea el de Cortés Moreno (2001). En dicha área son dignos de mención los meritorios artículos de Hsieh (2006a, 2006b, 2007 y 2008), López Portillo (2011), Rubio Lastra (2008) y Tang (2002), en los que se analiza la motivación por el aprendizaje del ELE en diferentes universidades taiwanesas. Los hallazgos de estos autores y los nuestros coinciden, p. ej., en señalar que la mayoría de los universitarios taiwaneses que optan por estudiar español confían en que los conocimientos de esta lengua les ayudarán a conseguir un empleo ventajoso y les resultarán de utilidad para sus viajes (de turismo). Como obra de referencia general, es recomendable la de Sánchez Griñán y Melo (2009). Asimismo, nos ha resultado de interés la consulta de Trujillo Sáez (2005).

\section{Objetivos}

Los tres objetivos de la entrevista que vamos a examinar son: (1) analizar la situación general de los estudiantes de $1 .{ }^{\text {er }}$ curso del Departamento de Español de la Universidad Fujen, (2) caracterizar su motivación por el ELE y (3) averiguar sus preferencias en torno a diversos componentes del proceso de aprendizaje.

Comparar los intereses y necesidades de los alumnos de ELE con los conocimientos que les ofrece el Departamento de Español nos permiti-

1 Para una sucinta revisión del estado de la cuestión sobre el tema, v. Cortés Moreno (2013C). 
rá evaluar en qué medida la oferta educativa se ajusta a la demanda discente. Una vez detectados los desajustes entre la oferta y la demanda, nos proponemos acometer una reforma del currículo de ELE, adaptándolo a los intereses, necesidades y expectativas de los estudiantes taiwaneses de esta década.

En definitiva, nuestro objetivo primordial y general es aportar sugerencias concretas y viables (v. Cortés Moreno, 2001, 2012b y 2013b), encaminadas a adaptar la enseñanza a las expectativas de aprendizaje de los estudiantes taiwaneses de ELE y, al mismo tiempo, a elevar su motivación por el ELE.

\section{Hipótesis}

1) Los alumnos del Departamento de Español de la Universidad Fujen son conscientes de que esta es una lengua muy importante $y$, por regla general, muestran un nivel suficiente de motivación por su aprendizaje.

2) Los alumnos tienen opiniones razonadas en torno a qué asignaturas les resultan interesantes y útiles.

3) Los alumnos tienen opiniones razonadas en torno a qué actividades y qué materiales de aprendizaje son interesantes y útiles.

4) Los alumnos tienen opiniones razonadas en torno a qué técnicas de enseñanza se adaptan mejor a sus propios estilos y estrategias de aprendizaje.

5) Cuanto más satisfechos se sientan los alumnos con los aspectos citados en las hipótesis anteriores - asignaturas, actividades, materiales y técnicas de enseñanza-, tanto más probable es que se sientan motivados por el aprendizaje del ELE.

\section{Metodología}

En esta investigación en el aula para la acción, como instrumento para la recogida de datos de primera mano recurrimos a una entrevista. Una de las principales ventajas de la entrevista individual es que permite tratar en profundidad cada tema elegido, deshacer posibles ambigüedades, matizar afirmaciones y sugerencias e incluso adentrarse en nuevas cuestiones de interés que puedan surgir sobre la marcha.

Un inconveniente de la entrevista es que se requiere una mayor dedicación de tiempo a cada informante que, p. ej., en el caso de una encuesta a todo un grupo de alumnos a la vez. Otro inconveniente es que cuando los entrevistados son los propios alumnos del entrevistador resulta difícil mantener el anonimato frente al profesor. Ahora bien, difícil no significa imposible, puesto que se pueden emplear técnicas y estrategias alternativas de recogida de datos que le garanticen al entrevistado el anonimato. Una de ellas consiste en recurrir a ayudantes de investigación que actúen como intermediarios entre el profesor/investigador y los alumnos/entrevistados, es decir, los ayudantes de investigación, quienes, en principio, no conocen a los alumnos, se encargan de entrevistarlos cara a cara y posteriormente transmiten la información obtenida al investigador principal (el profesor), sin facilitarle el nombre de cada entrevistado, sino únicamente un número o código de informante. Al quedar salvaguardadas las declaraciones de los entrevistados, es más probable obtener respuestas sinceras, con las que podremos dibujar una imagen fidedigna de la situación y extraer conclusiones fiables.

La entrevista que nos ocupa aquí consta de 20 ítems en torno a diversos aspectos del aprendizaje del ELE: asignaturas, materiales utilizados en clase, utilidad del español para su vida actual, etc. El protocolo de aplicación de la entrevista es el siguiente. En primer lugar, nuestras ayudantes de investigación le envían por correo electrónico en diciembre de 2012 a cada alumno (30 voluntarios, en total) el cuestionario bilingüe (español- 
chino) de la entrevista, con el fin de que estos tengan tiempo de reflexionar sobre cada uno de los 20 ítems, pensar las respuestas concretas, escribir un borrador con ellas (ya sea en español o en chino) y devolvérselo por correo electrónico. Unas semanas más tarde (en enero-febrero de 2013), con la colaboración de nuestras ayudantes de investigación procedemos a la entrevista cara a cara, ocasión que se aprovecha para pedir aclaraciones o precisiones de las ideas esbozadas en los borradores.

\section{Resultados de la entrevista}

En este apartado vamos a analizar los resultados de los 20 ítems que componen la entrevista. En cada caso consignamos un resumen gráfico con datos porcentuales. Si bien los enunciados se presentan a los alumnos en versión bilingüe (español-chino), para ahorrar espacio, aquí transcribiremos únicamente la versión española.

1. Exactamente, ¿tú por/para qué deseas y/o necesitas aprender español?

\section{GRÁFICO 1}

Resultados en el ítem 1

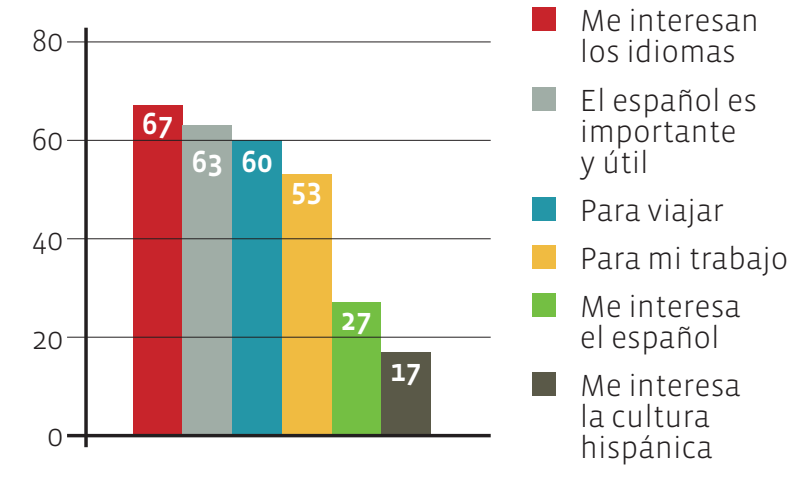

Los datos recogidos en este ítem parecen corroborar la primera hipótesis: los alumnos son plenamente conscientes de la importancia del español; sienten un claro interés por los idiomas, en general, y por el español, en particular, y esperan que esta lengua les sirva tanto para fines profesionales como para viajar. Todo ello apunta a que muestran un nivel suficiente de motivación por el ELE.

2. ¿Crees que el español te será útil en tu carrera profesional?

\section{GRÁFICO 2}

Resultados en el ítem 2

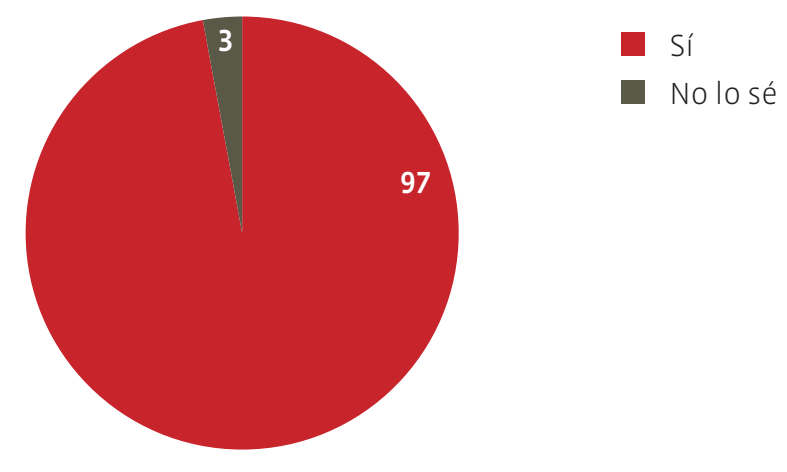

3. De las asignaturas de español que tienes este semestre, ¿cuáles te parecen más interesantes?

\section{GRÁFICO 3}

Resultados en el ítem 3

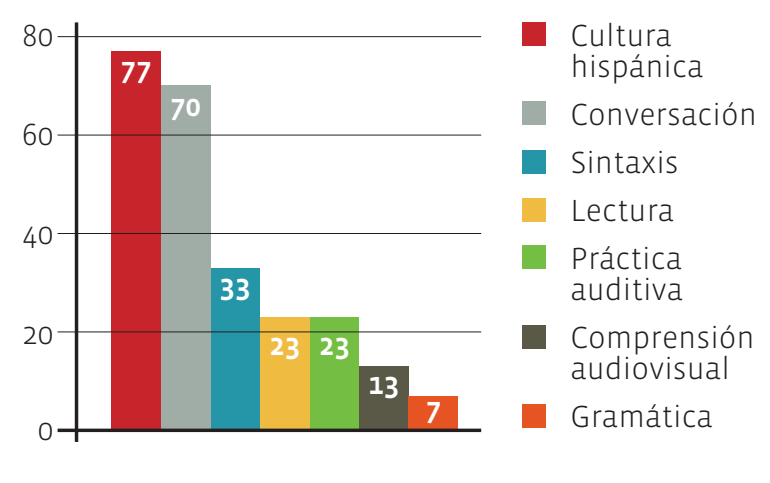

La elección de las asignaturas citadas responde principalmente a estas cuatro razones: (1) el interés de los contenidos (23\%), (2) la utilidad de las clases (17\%), (3) las oportunidades que se brindan para practicar (13\%) y (4) la sensación de entender bien y aprender mucho (10\%).

4. De las asignaturas de español que tienes este semestre, ¿se podría(n) quitar alguna(s)? 


\section{GRÁFICO 4}

Resultados en el ítem 4

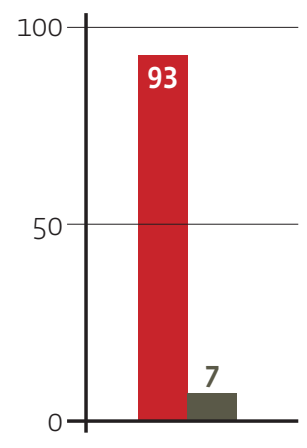

Existe consenso en torno a la importancia de todas las asignaturas del 1. ${ }^{\text {er }}$ semestre de español, con tan solo dos únicas excepciones: Gramática y Sintaxis, "porque los contenidos de las clases de Gramática y de Sintaxis son casi iguales", una razón comprensible, dado que la sintaxis forma parte de la gramática².

5. Aparte de las asignaturas que tienes ahora, ¿qué otras asignaturas de español te gustaría tener?

\section{GRÁFICO 5}

Resultados en el ítem 5
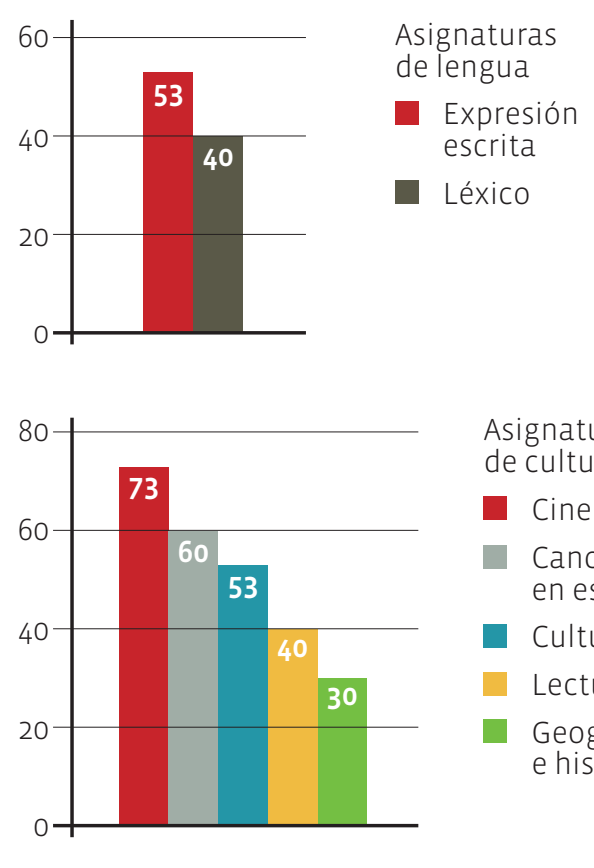

Asignaturas de cultura

- Cine en español

Canciones en español

- Cultura hispánica

- Lectura literaria

- Geografía e historia

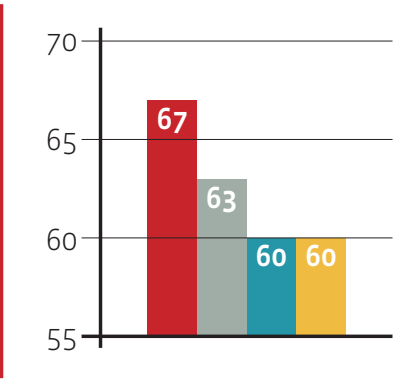
Asignaturas
de orientación
profesional
- Rel. internacionales / Diplomacia
- Español turismo
- Español hostelería
- Español comercial

Se aprecia una demanda considerable, por un lado, de asignaturas de cultura y, por otro lado, en igual medida, de asignaturas de orientación profesional. La principal razón (mencionada por el 20\%) por la que proponen dichas asignaturas coincide con la apuntada en el ítem 3: porque atribuyen a sus contenidos un al to grado de interés y utilidad.

6. ¿Qué asignaturas consideras más importantes para tu formación como estudiante universitario?

\section{GRÁFICO 6}

Resultados en el ítem 6

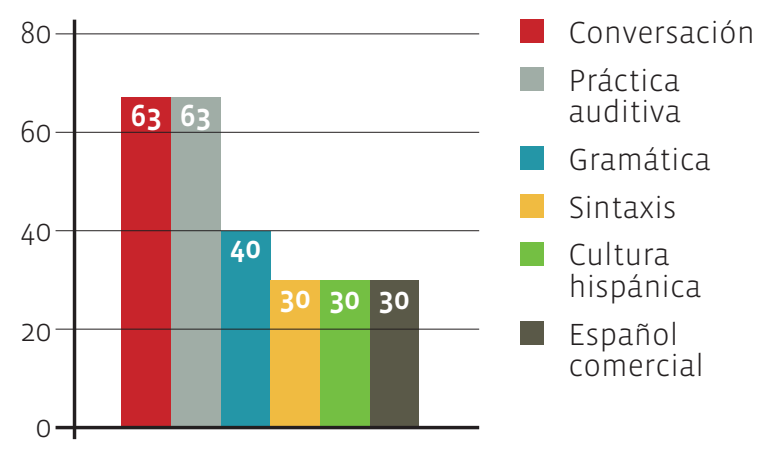

Según los datos recogidos en este ítem, las asignaturas más importantes para su formación como estudiantes universitarios son Conversación y Práctica Auditiva. Ahora bien, si sumamos los datos relativos a Gramática y a Sintaxis (que, como es sabido, forma parte de la gramática), la categoría resultante pasa a ocupar la primera posición en la clasificación. En efecto, la mayoría de los alumnos le atribuyen a la teoría gramatical un papel preponderante, por considerarla la base de la lengua. Esta creencia tradicional

2 Sobre la pertinencia de enseñarles gramática, véase Cortés Moreno (2005). 
carece de fundamento científico; de hecho, la pragmática es tan fundamental para la comunicación como la gramática. Con todo, el aplastante peso de la tradición secular no deja margen para un cuestionamiento del papel nuclear de la gramática, tanto en la enseñanza de la LE, como en el sistema de evaluación. En tales circunstancias, resulta lógico que los estudiantes se esfuercen por aprenderla, para así lograr aprobar y graduarse sin impedimentos.

La elección de las asignaturas citadas responde a tres razones principales: (1) a la creencia de que constituyen la base de la lengua (43\%), (2) a la convicción de que les resultarán útiles en el futuro (30\%) y (3) al interés de los contenidos (27\%).

7. ¿Qué asignaturas consideras más importantes para tu futuro?

\section{GRÁFICO 7}

Resultados en el ítem 7

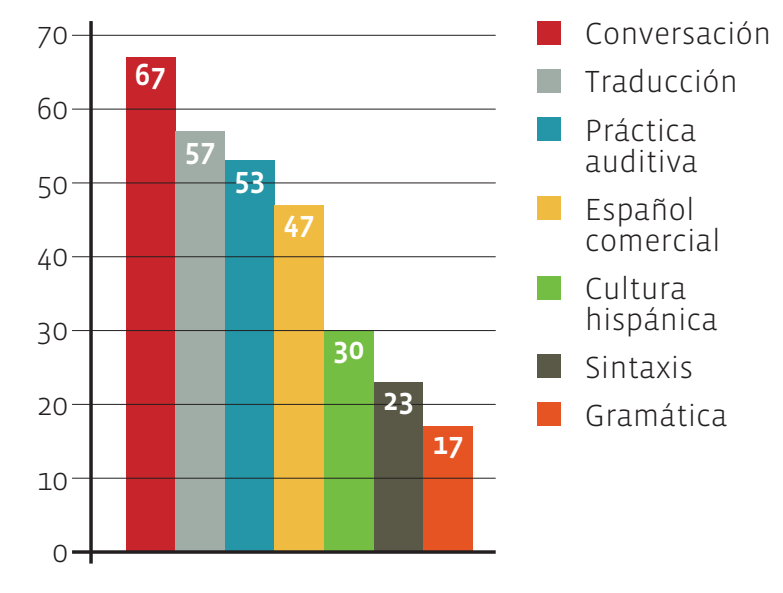

Al igual que en el ítem anterior, Conversación ocupa el primer puesto entre las preferencias de los entrevistados. Práctica Auditiva también se mantiene entre las tres primeras posiciones. En cambio, Gramática + Sintaxis $(23 \%+17 \%=40 \%)$ descienden al $5 .^{\circ}$ puesto $\mathrm{y}$ Cultura al $6 .^{\circ}$, por una sencilla razón: cuando los alumnos piensan en su futuro después de graduarse, otorgan mayor valor a otras asigna- turas más prácticas, de orientación profesional, tales como Traducción y Español Comercial. El contraste entre las respuestas obtenidas en los ítems 6 y 7 demuestra que estos estudiantes disciernen a la perfección entre sus objetivos presentes en la vida universitaria y sus objetivos futuros en la vida laboral.

La elección de las asignaturas citadas responde a dos razones principales: (1) a la convicción de que les resultarán útiles en el futuro (33\%) y (2) a la creencia de que constituyen la base de la lengua (27\%).

8. ¿Quién debería decidir los contenidos que vas a aprender en cada asignatura, los temas que se van a tratar en clase, etc? ¿El profesor? ¿Los alumnos?

\section{GRÁFICO 8}

Resultados en el ítem 8

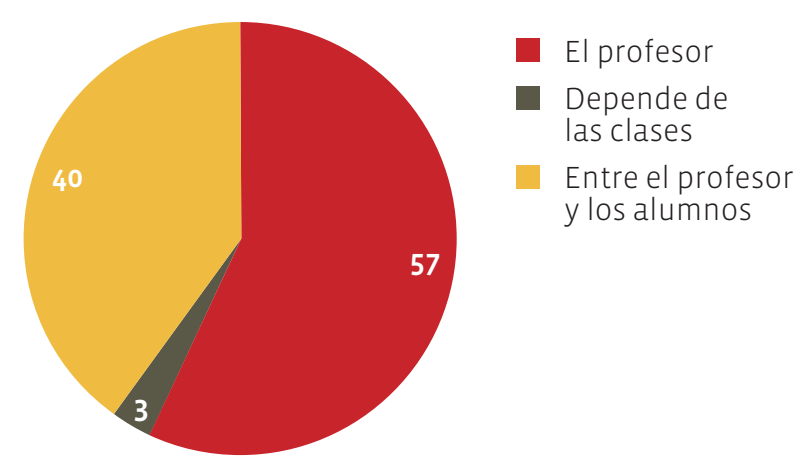

Adviértase que al formular este ítem nos abstuvimos de plantear la opción (ideal, a nuestro juicio) "Entre el profesor y los alumnos", porque temíamos que el mero hecho de mencionarla induciría a los entrevistados a elegirla, con lo que la respuesta quedaría condicionada de antemano. A pesar de todo, a 4 de cada 10 de ellos se les ocurre esta fórmula de negociación conjunta, aun cuando la mayoría opta por la fórmula tradicional: el profesor se responsabiliza de todas las decisiones.

9. ¿Qué tipos de materiales didácticos te resultan más motivadores? 


\section{GRÁFICO 9}

Resultados en el ítem 9

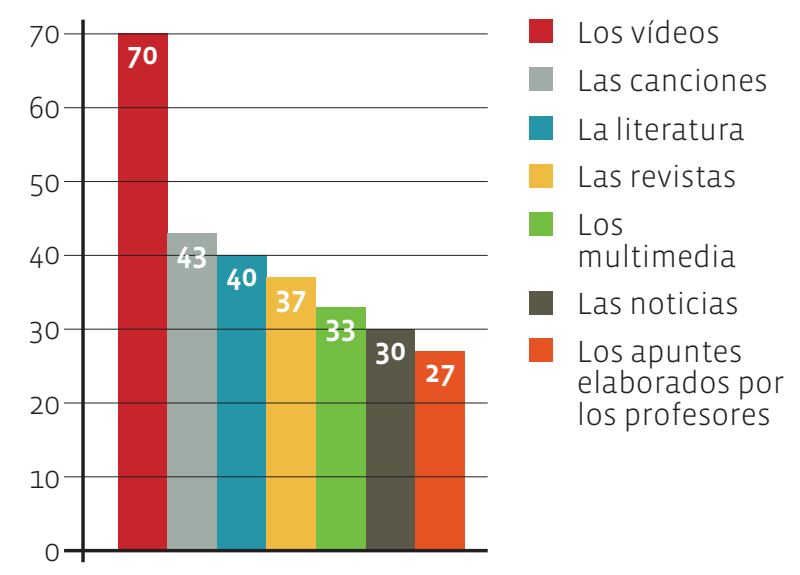

Queda patente que los materiales preferidos por 7 de cada 10 alumnos son los vídeos. A una distancia considerable figura una escalera de opciones, desde un $27 \%$ hasta un $43 \%$. Se observa un equilibrio entre las preferencias por los materiales relacionados con la lengua oral (vídeos, canciones, multimedia) y los relacionados con la lengua escrita (literatura, revistas, noticias, apuntes). Asimismo, se aprecia un cierto equilibrio entre el interés por la lengua y el interés por la cultura.

La elección de los materiales citados responde a tres razones principales: (1) porque los consideran interesantes (33\%), (2) porque les ayudan a conocer la cultura de los nativos (30\%) y (3) porque les ayudan a aprender el uso auténtico y actual del español (23\%).

10. A) ¿Qué tipos de materiales de español te gustan más? B) ¿Cuáles te gustan menos? C) ¿Qué sugerirías tú para mejorar los materiales de español?

En definitiva, las características más valoradas en los materiales de enseñanza y aprendizaje son: (1) que se combinen los canales de recepción del mensaje (multimedia) —básicamente, visual y auditivo-, (2) que se combinen palabras e imágenes, (3) que faciliten el aprendizaje, (4) que se atienda a todas las destrezas lingüísticas,

\section{GRÁFICO 10}

Resultados en el ítem 10A (Me gustan...)

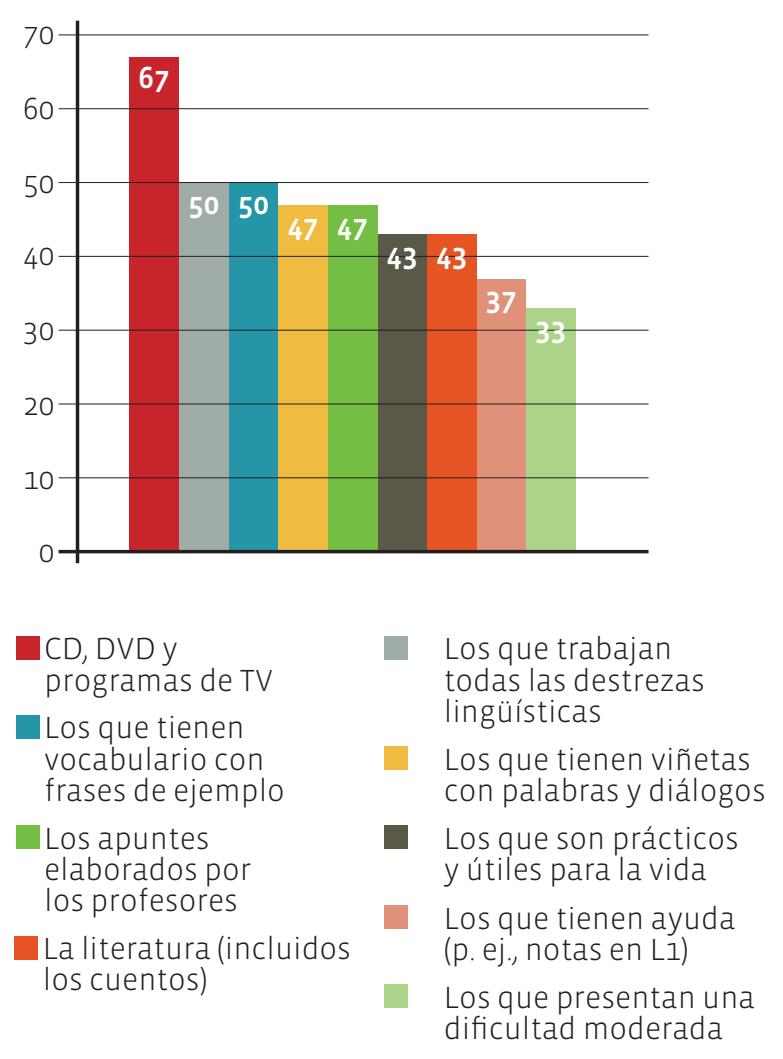

\section{GRÁFICO 11}

Resultados en el ítem 10B (No me gustan...)

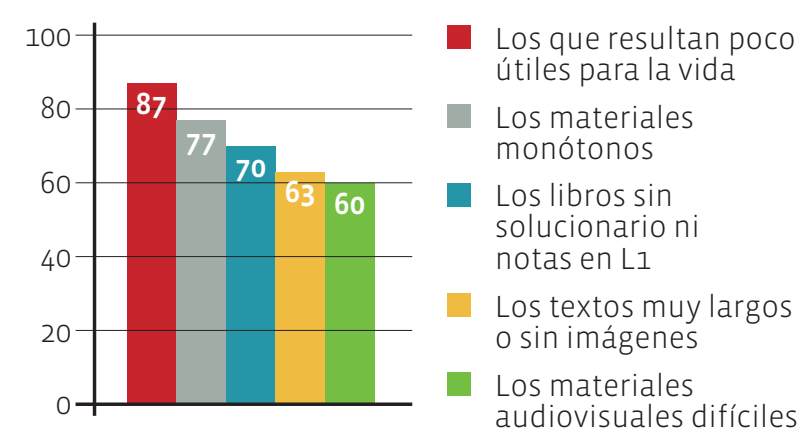

(5) que resulten prácticos y útiles y (6) que entrañen una dificultad moderada. Por el contrario, los materiales didácticos más criticados son: (1) los que implican una excesiva dificultad, (2) aquellos que parecen poco útiles para la vida y (3) los que resultan monótonos y aburridos. En el 
apartado (C) de este ítem, 1 de cada 5 alumnos propone la utilización de materiales más variados, más prácticos, más atractivos y que faciliten el aprendizaje, en definitiva, unos materiales adaptados a los estudiantes taiwaneses de ELE.

11. De todas las actividades de aprendizaje que haces en las clases de español (o de otras lenguas), ¿cuáles te parecen más interesantes?

\section{GRÄFICO 12}

Resultados en el ítem 11

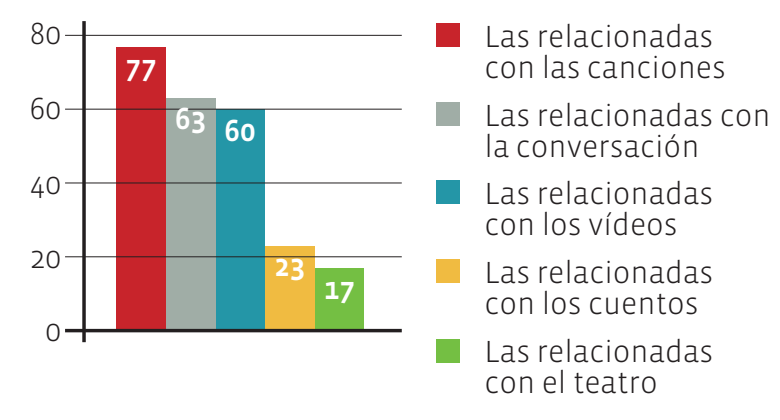

La mayoría se decanta por actividades orales; solo una minoría opta por las escritas.

12. De las diferentes técnicas de enseñanza que usan tus profesores de español y de otras lenguas, ¿cuáles te parecen más motivadoras?

\section{GRÁFICO 13}

Resultados en el ítem 12

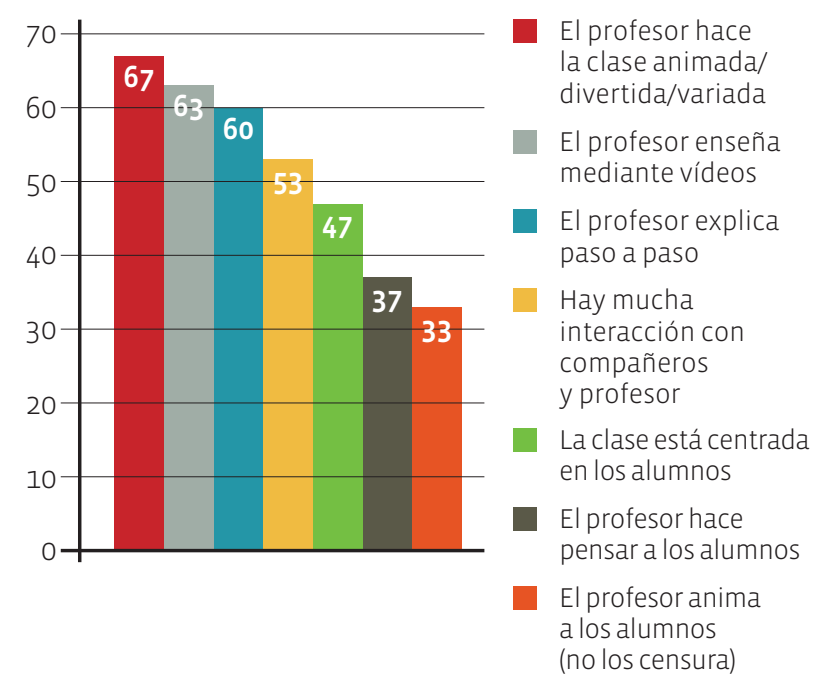

Las opciones más escogidas aluden a diferentes componentes de la metodología aplicada en el aula: al planteamiento curricular y metodológico —clase centrada en los alumnos-, a los contenidos _clase animada / divertida / variada- y a los materiales -empleo de vídeos-, pero, por encima de todo, aluden a la actuación docente - el profesor explica paso a paso, se produce abundante interacción entre los alumnos y con el profesor, este hace pensar a los alumnos y los anima a participar, no los censura por sus errores-.

\section{3. ¿Podrías describir la clase ideal de español?}

\section{GRÁFICO 14}

Resultados en el ítem 13

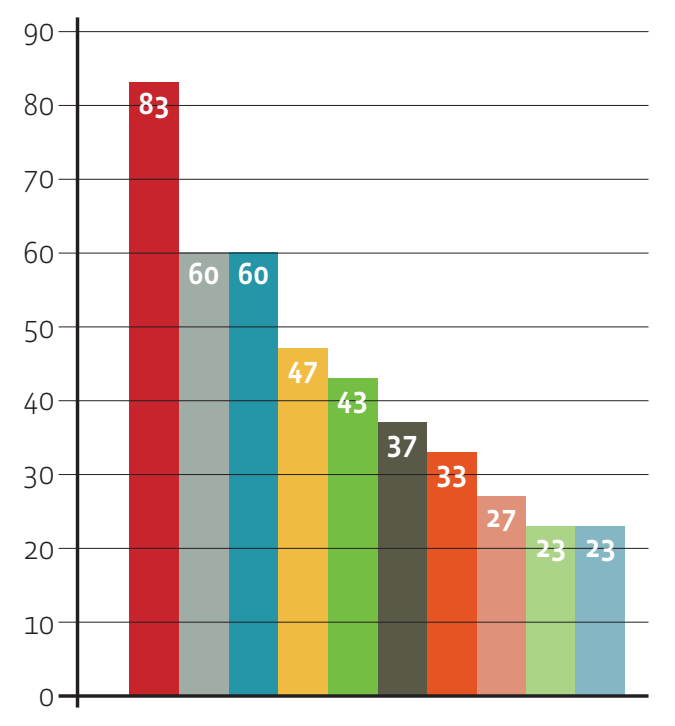

Hay ambiente agradable (aprendizaje+diversión)

- Los alumnos prestan mucha atención

- Se emplean materiales muy variados

Los alumnos adquieren conocimientos útiles

Las actividades son

variadas y animadas

El profesor es motivador (interesante/divertido)

- Se trabajan contenidos muy variados

- El profesor prepara bien la clase

se habla mucho en español y (casi) nada en $L 1$

Hay mucha interacción entre alumnos y profesor

En resumidas cuentas, una clase ideal es aquella en la que reina un ambiente agradable 
y se propicia una constante interacción en español entre todos los participantes, quienes ponen el máximo interés y esfuerzo en llevar a cabo una serie de tareas didácticas variadas y útiles para la vida.

14. ¿Dirías que en las clases de español hay un ambiente favorable al aprendizaje?

\section{GRÁFICO 15}

Resultados en el ítem 14

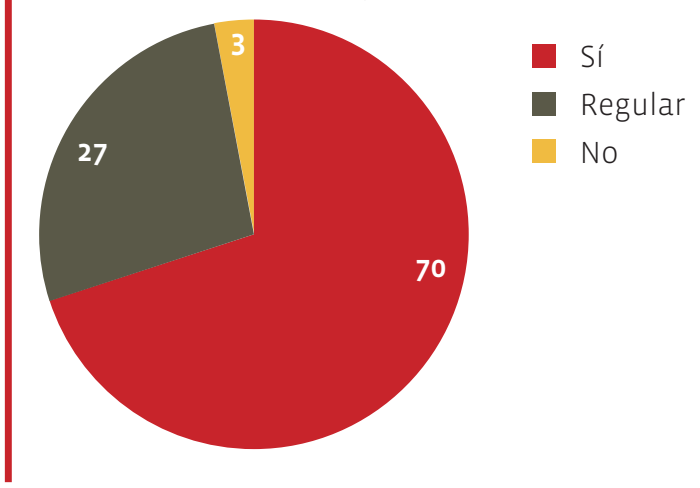

Simplificando los resultados, se puede afirmar que de cada 3 entrevistados 2 opinan que el ambiente existente propicia el aprendizaje, mientras que 1 manifiesta ciertas reservas al respecto. Las razones esgrimidas, tanto en la repuesta afirmativa como en la negativa, son de diversa índole; conciernen a los contenidos, los materiales, el método, etc. La única opción que descuella es la práctica del español en el aula. Convenimos en que el empleo del español como lengua vehicular constituye un valioso elemento motivador, puesto que así los alumnos principiantes empiezan a concienciarse de la utilidad de esta lengua.

15. ¿Qué tipos de tareas para casa te parecen más interesantes?

Aun cuando tradicionalmente las tareas o deberes para casa se asocian preponderantemente con ejercicios de lectoescritura, las preferencias de estos jóvenes entrevistados ponen de relieve un perfecto equilibrio entre la lengua oral (vídeos + canciones = 87\%) y la escrita (lectu-

\section{GRÁFICO 16}

Resultados en el ítem 15

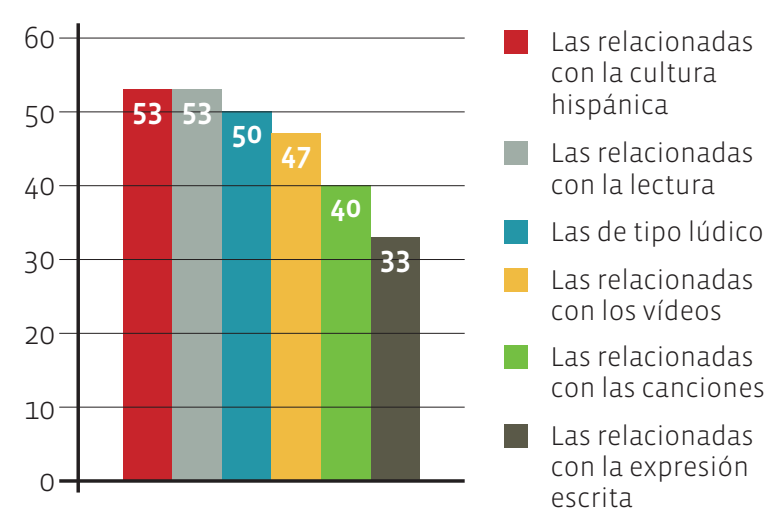

ra + expresión escrita = 87\%). Otros tipos de tareas propuestas por la mitad de los alumnos son las relacionadas con la cultura hispánica y las de carácter lúdico; unas y otras pueden ser tanto orales como escritas o mixtas.

16. ¿Quién es el responsable de que tú estudies en casa?

\section{GRÁFICO 17}

Resultados en el ítem 16

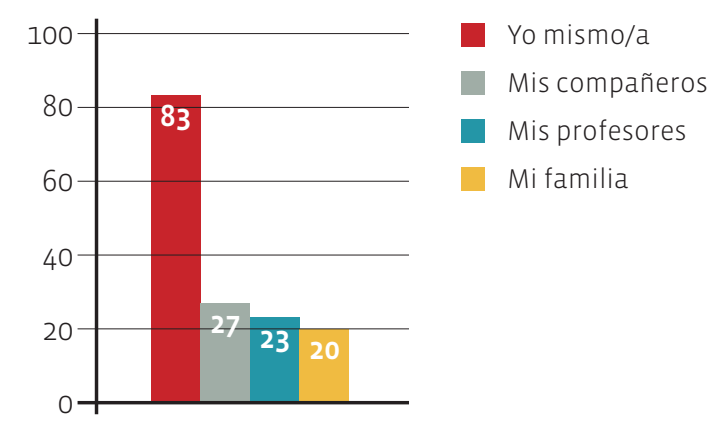

A pesar de su juventud ( \pm 18 años), la inmensa mayoría de los entrevistados consideran que ellos mismos son los principales responsables de estudiar en casa. Ahora bien, 2 de cada 3 creen que esa responsabilidad es compartida con otras personas, en proporciones equiparables: los familiares, los profesores y los compañeros.

17. ¿Qué podemos hacer los profesores para animarte a estudiar y practicar español fuera de clase? 


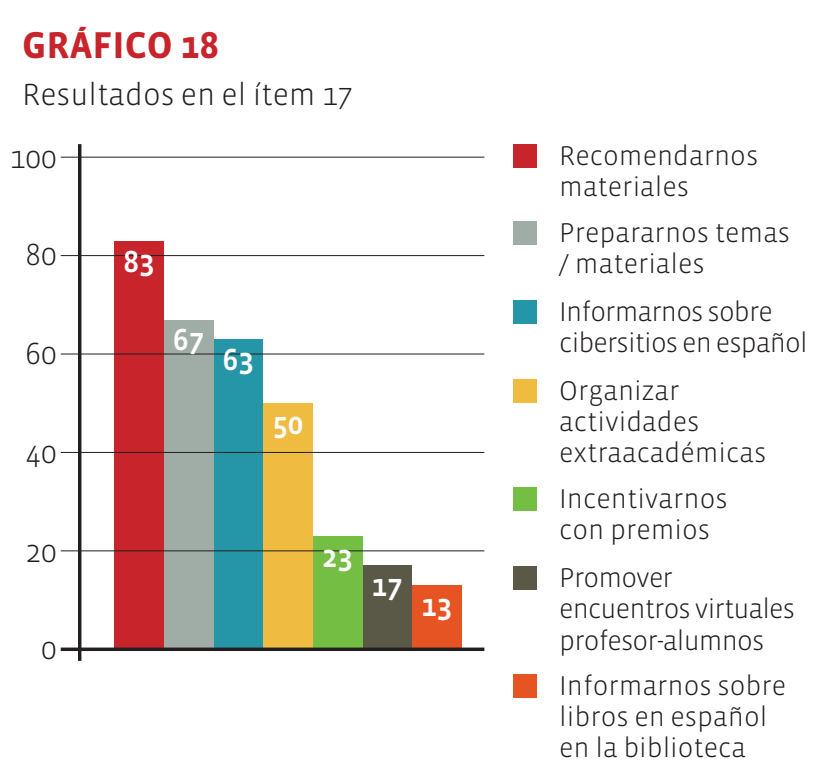

Las propuestas van encaminadas mayormente en tres sentidos: (1) asesorar a los alumnos, preparándolos para un aprendizaje en autonomía o autodirigido, (2) proporcionarles herramientas para el aprendizaje y práctica de la LE en el aula y (3) organizar actividades extraacadémicas, presenciales o virtuales, con el fin de que puedan seguir progresando fuera de las clases.

18. ¿Podrías describir al profesor / a la profesora ideal?

Probablemente, a nadie le sorprenda que los entrevistados consideren importante que el profesor sea un profesional responsable e imparcial, que transmita con claridad conocimientos útiles y que cree oportunidades para practicar español. Sin embargo, quizá pueda llamar la atención que por encima de esas virtudes y saberes se valoren otros aspectos relacionados no tanto con la formación docente, sino más bien con la personalidad y la actitud del profesor, sobre todo, con su capacidad para adaptar la enseñanza a las necesidades y a los intereses específicos de los alumnos, pero también con su grado de simpatía, paciencia y amabilidad, así como con su perspicacia para crear un ambiente distendido y propicio para la diversión y el aprendizaje.

\section{GRÁFICO 19}

Resultados en el ítem 18

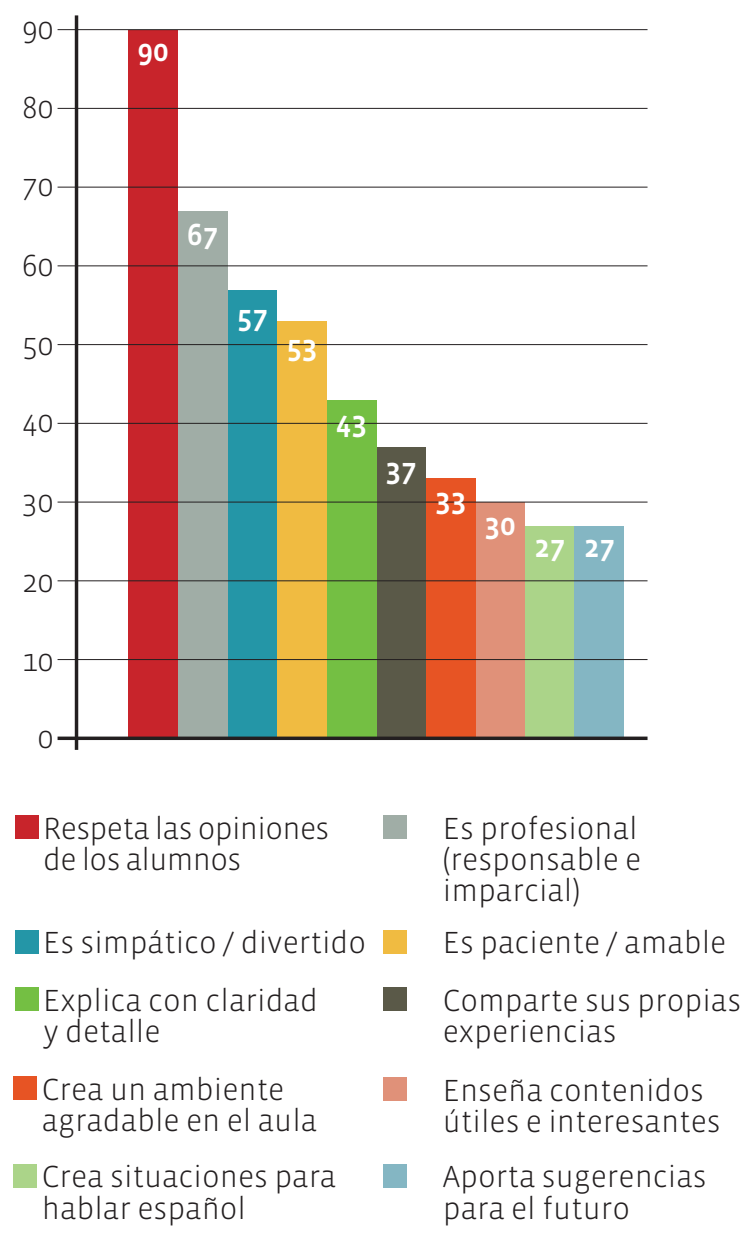

19. Si tú fueras profesor/a, ¿qué harías para motivar a tus alumnos?

Atendiendo a las propuestas de los alumnos, en primer lugar conviene averiguar sus expectativas, para así poder no solo hacer las clases más interesantes y divertidas, enseñando contenidos prácticos, sino también organizar actividades extraacadémicas apropiadas y orientar a los alumnos en el aprendizaje, creando con todo ello múltiples oportunidades para aprender y practicar español. En paralelo, parece aconsejable entablar una relación cordial entre el profesor y los alumnos, esencial para instaurar un ambiente agradable que propicie la participación activa de todos los alumnos. 


\section{GRÅFICO 20}

Resultados en el ítem 19

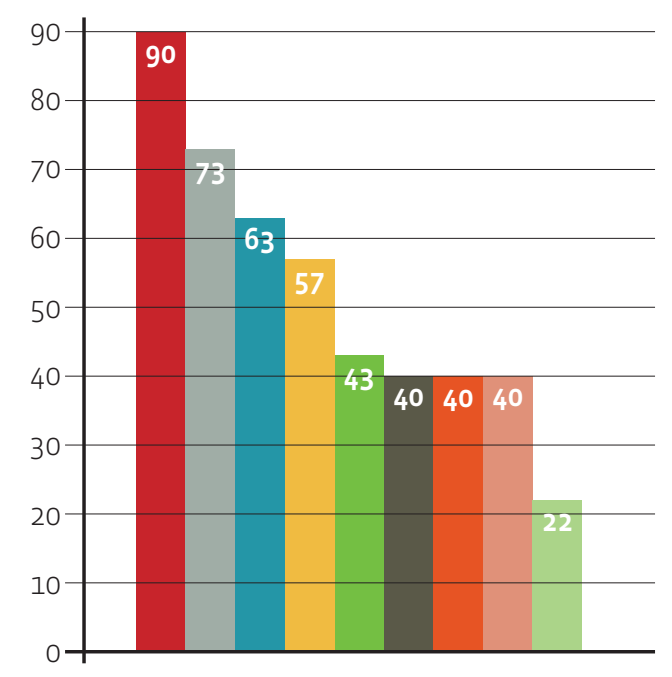

Animarlos a practicar

Averiguar sus intereses

Entablar una buena relación con los alumnos

Enseñar contenidos prácticos para la vida

Asesorarlos sobre el aprendizaje

20. ¿Se te ocurre alguna otra idea importante sobre el tema de la motivación por el aprendizaje del español?

Tan solo $1 / 3$ de los encuestados se sienten inspirados para formular alguna sugerencia adicional, mayormente en la línea de las ya esbozadas en los ítems anteriores. He aquí cuatro de ellas: (1) la utilidad de saber español, p. ej., para la búsqueda de empleo, (2) la importancia de practicar español, (3) la importancia de elegir temas, actividades y materiales variados y sugestivos para la clase y (4) la beneficiosa influencia del modelo del profesor.

\section{Conclusiones}

Cada una de las 5 hipótesis de partida ( $v$. apartado 3) ha quedado confirmada con los resultados de la entrevista. En efecto, los alumnos entrevistados son conscientes de que el español es una lengua muy importante y, por regla general, muestran un nivel suficiente de motivación por su aprendizaje (hipótesis 1). Asimismo, tienen opiniones razonadas en torno a qué asignaturas les interesan (hipótesis 2), qué actividades y qué materiales de aprendizaje prefieren (hipótesis 3) y qué técnicas de enseñanza se adaptan mejor a sus propios estilos y estrategias de aprendizaje (hipótesis 4). Por último, constatamos una correlación entre el grado de satisfacción con los aspectos abordados en las hipótesis anteriores (asignaturas, actividades, materiales, etc.) y el grado de motivación por el aprendizaje del ELE (hipótesis 5).

Nos congratulamos de que, por regla general, los alumnos entran en el Departamento de Español con un nivel satisfactorio de motivación por el ELE. Ahora bien, tengamos en cuenta que tal nivel se mantendrá, aumentará o disminuirá, en función de lo que ocurra a lo largo de su carrera, tanto en el aula como fuera de ella. Por tanto, es esencial que los profesores tomemos las medidas oportunas para ir reforzando esa motivación inicial y minimizando aquellos factores que pudieran mermarla.

De los 7 primeros ítems de la entrevista se desprende que los alumnos del Departamento de Español confían en que esta lengua les sirva, tanto para fines profesionales como para fines personales (p. ej., turísticos). De ahí que muestren el máximo interés no solo por asignaturas de orientación profesional (sobre todo, Traducción y Español Comercial), sino también por asignaturas de cultura hispánica; con todo, la asignatura que más les complace y que más útil consideran es Conversación.

A lo largo del apartado anterior hemos tenido ocasión de constatar en repetidas ocasiones cómo los entrevistados han sido capaces de formular propuestas atinadas, argumentadas y viables para mejorar su situación de aprendizaje. Parecería sensato tenerlas en cuenta a la hora 
de diseñar un currículo de ELE. Aprovechamos algunas de esas ideas y las combinamos con otras recopiladas en diversas entrevistas y encuestas anteriores, para seguir elaborando una propuesta general, cuyo primer borrador se esbozó en Cortés Moreno (2012a), que no pretende ser exhaustiva ni ejemplar, sino tan solo un punto de partida para la construcción de un futuro modelo que englobe la actividad docente y discente antes de, durante y después de la clase de ELE. He aquí un segundo borrador de la propuesta en cuestión:

\section{A) Antes de la clase:}

- Averiguar las expectativas de los alumnos acerca del contenido de las clases, las actividades y materiales de aprendizaje, el método de enseñanza, etc.

- Negociar con los alumnos el plan de estudios de la carrera (currículo), el de cada curso y el de cada asignatura; negociar en cada asignatura las actividades didácticas, los temas, los materiales, las tareas para casa, el sistema de evaluación, etc. Esa negociación contribuirá a que los alumnos se responsabilicen de su propio aprendizaje y se sientan más motivados.

- Planificar clases centradas en los intereses y necesidades de los alumnos, procurando incluir tareas y conocimientos prácticos para la vida real.

- Programar para cada clase una amplia variedad de contenidos, de actividades, de materiales... Esa variedad, además de ser un factor de motivación, beneficia a todos los alumnos, puesto que cada uno tiene su propio estilo de aprendizaje.

- Buscar materiales que resulten útiles y que conlleven una dificultad moderada; dar preferencia a los diseñados para (o adaptados a) los estudiantes taiwaneses de ELE.

- Aun cuando la mayoría de los alumnos muestran una predilección palmaria por las activi- dades orales (p. ej., diálogos, debates, visualización de vídeos, escucha de canciones, etc.), parece sensato atender también en su justa medida a las actividades escritas (p. ej., las relacionadas con las revistas, la literatura, los correos electrónicos y cibercharlas, etc.).

B) En el aula:

- Ser amable, paciente y simpático con los alumnos; mantener el sentido del humor; enseñar con entusiasmo.

- Crear un ambiente agradable, relajado y cordial.

- Organizar una constante interacción entre el profesor y los alumnos.

- Motivar continuamente a los alumnos, para que mantengan la atención durante toda la clase; animarlos a participar al máximo en español.

- Llevar a cabo una serie de tareas didácticas variadas y útiles para la vida.

- Buscar un equilibrio entre los materiales relacionados con la lengua oral y los relacionados con la lengua escrita.

- Aprovechar la tecnología de la información y la comunicación y los materiales multimedia, muy en especial los vídeos y los que combinan palabras e imágenes.

- Explicar paso a paso y con claridad; adaptar la clase al ritmo de los alumnos y a sus intereses en cada momento.

- Procurar que la clase resulte variada, interesante, entretenida, animada y divertida; tener presente que el componente lúdico y la diversión son excelentes aliados del aprendizaje y de la motivación.

- Resaltar más los aciertos de los alumnos que sus errores; tratar estos como un fenómeno natural en el aprendizaje; corregir sin censurar, procurando no frustrar; ser imparcial.

- Recompensar el esfuerzo y el progreso.

- Recordarles a menudo a los alumnos: 
1) la importancia de la lengua española en el mundo: alrededor de 500.000.000 de hablantes, una de las 3 más internacionales, una de las 6 oficiales en la ONU, así como en 21 países, la 2. ${ }^{a}$ más estudiada, etc.;

2) la utilidad de saber español, p. ej., para la búsqueda de empleo o para viajar y conocer a otras personas y sus culturas;

3) la necesidad de practicar para progresar en el aprendizaje.

C) Para después de la clase:

- Aparte de las tradicionales tareas de lectoescritura, asignarles otras de lengua oral, p. ej., basadas en vídeos y canciones; atender también a la cultura.

- Recomendarles materiales y actividades de aprendizaje apropiadas a su nivel y a sus necesidades.

- Formarlos como aprendientes autónomos o autodirigidos, capaces de procurarse por sí mismos los materiales de aprendizaje ideales para sus propios intereses y necesidades.

- Organizar con los alumnos (y con otros profesores) actividades extraacadémicas apropiadas, divertidas y útiles, ya sean presenciales o virtuales, con el fin de que puedan seguir aprendiendo español fuera del aula.

D) En cualquier momento en el Departamento de Español:

- Emplear el español como lengua vehicular en todas las dependencias del Departamento de Español: despachos, aulas, pasillos, etc. La creación de un ambiente hispanohablante contribuirá a concienciar a los alumnos de la utilidad del español en su vida cotidiana, lo que redundará en beneficio de su motivación por el aprendizaje.

\section{Bibliografía citada}

Cortés Moreno, Maximiano, 2001: “AAprender español en Taiwán?: El factor motivación”, Glosas
Didácticas, Revista Electrónica Internacional de la Sociedad Española de Didáctica de la Lengua y la Literatura 7 [http://203.68.184.6:8080/dspace/bitstream/987654321/275/1/Microsoft\%20 Word\%20-\%2015\%202001\%20APRENDER\%20 ESPAN O L\%20EN\%20TAIWAN.\%20EL\%20FACTOR\%20MOTIVACION\%20_GI.pdf, fecha de consulta: 10 de septiembre de 2013].

Cortés Moreno, Maximiano, 2005: “¿Hay que enseñar gramática a los estudiantes de una lengua extranjera?", CAUCE, Revista Internacional de Filología y su Didáctica 28, 89-108.

Cortés Moreno, Maximiano, 2009: "La motivación por el aprendizaje del ELE en China: propuestas para potenciarla", MarcoELE 8 [http://marcoele. com/descargas/china/cortes_motivacion.pdf, fecha de consulta: 10 de septiembre de 2013].

Cortés Moreno, Maximiano, 2011: “¿Cómo puedo motivar a mis alumnos de ELE?: análisis de un caso en Taiwán”, Actas del VII Congreso Internacional de la Asociación Asiática de Hispanistas, Universidad de Estudios Extranjeros de Pekín, 206-220.

Cortés Moreno, Maximiano, 2012a: "Nuestro currículo de español no es perfecto", SinoELE 6, 84102 [http://www.sinoele.org/images/Revista/6/ cortes_84-102.pdf, fecha de consulta: 10 de septiembre de 2013].

Cortés Moreno, Maximiano, 2012b: “¿Qué opinan los alumnos taiwaneses sobre el currículo de ELE?", SinoELE 7, 24-77 [http://www.sinoele.org/ index.php?option=com_content\&view=article \&id=187\&lang=es, fecha de consulta: 10 de septiembre de 2013].

Cortés Moreno, Maximiano, 2013a: "Expectativas de los alumnos taiwaneses de ELE: una encuesta a principiantes universitarios", SinoELE 8, 42-75 [http://www.sinoele.org/images/Revista/8/Articulos/mcortes_42-75.pdf, fecha de consulta: 10 de septiembre de 2013].

Cortés Moreno, Maximiano, 2013b: "Un currículo consensuado entre profesores y alumnos de ELE", MarcoELE 16 [http://marcoele.com/descargas/16/cortes-curriculo_consensuado.pdf, fecha de consulta: 10 de septiembre de 2013].

Cortés Moreno, Maximiano, 2013c: "Reforma del currículo de ELE atendiendo a las preferencias 
de los alumnos" en Miguel Ángel González (ed.): Desafíos y perspectivas de la enseñanza del español en Taiwán: diseño y programación de los cursos, Taipéi: Universidad Fujen.

DöRnYEI, Zoltán, 2001a: Motivational Strategies in the Language Classroom, Cambridge: C. U. P. DöRnYEI, Zoltán, 2001b: Teaching and Researching Motivation, Harlow: Pearson Education.

Gardner, Robert C., 1985: Social Psychology and Second Language Learning: The roles of attitude and motivation, Londres: Edward Arnold.

HsieH, S.-H., 2006a: La disposición para comunicarse en español de los aprendientes taiwaneses de E/LE (trabajo de investigación inédito), Madrid: Universidad Antonio Nebrija.

HsıeH, S.-H., 2006b: "La orientación motivacional de los estudiantes taiwaneses de E/LE", Actas del VIII Congreso de Didáctica del Español en la República de China, Taipéi: Servicio de Publicaciones de la Universidad Tamkang, 209-220.

HsIEH, S.-H., 2007: "La producción oral de los aprendientes taiwaneses de E/LE y la disposición para comunicarse", Actas del VIII Simposio Nacional: Estrategias para el aprendizaje del español, Taichung: Servicio de Publicaciones de la Universidad Providence.

Hsıer, S.-H., 2008: "El perfil de la orientación motivacional de los aprendientes taiwaneses de ELE", Actas del 5th Cross-Strait Conference on Foreign Language Teaching \& Learning, Káohsiung: Servicio de Publicaciones de la Universidad Wenzao.

López Portillo, Antonio, 2011: Factores que influencian en la motivación del aprendiente en el aprendizaje de español o inglés como lenguas extranjeras en una universidad de Taiwán, y en otra de Asunción, Paraguay, Universidad Autónoma de Asunción.

LoRenzo, Francisco, 2007: Motivación y segundas lenguas, Madrid: Arco.

Rubio Lastra, Miguel, 2008: "Actitud lingüística hacia la lengua española en el Colegio Universita- rio de Lenguas Wenzao", Encuentros en Catay 22, 179-214.

Sánchez Griñán, Alberto y Mónica Melo (compiladores), 2009: Qué saber para enseñar a estudiantes chinos, Buenos Aires: Voces del sur.

TANG, Yunting, 2002: "Análisis de la motivación del aprendizaje, su actitud y esfuerzo", Wenzao Journal 16, 545-562.

Trujlllo Sáez, Fernando, 2005: “La integración de lenguaje y contenidos en la enseñanza del español como segunda lengua en el contexto escolar", RedELE 4 [http://meteco.ugr.es/lecturas/ integra.pdf, fecha de consulta: 10 de septiembre de 2013]. 